\title{
Endoscopic Treatments of Pancreatic Incomplete Divisum (PID) in 20 Cases - Especially About Our New Procedures: Rendezvous Pre-Cut Method and Reverse Balloon Method
}

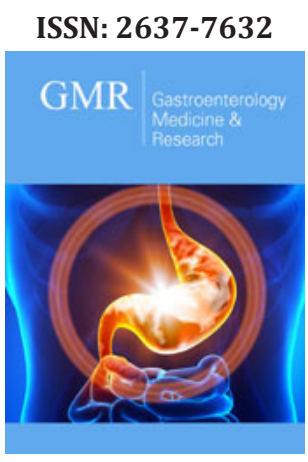

*Corresponding author: Tadao Tsuji, Saitama Cooperative Hospital, Gastroenterology, Japan

\section{Submission: 䟧January 23, 2020}

Published: 帮February 04, 2020

Volume 4 - Issue 2

How to cite this article: TadaoTsuji, Sun G, Sugiyama A, Amano Y, Mano S, et al. Endoscopic Treatments of Pancreatic Incomplete Divisum in 20 Cases Especially About Our New Procedures: Rendezvous Pre-Cut Method and Reverse Balloon Method. Gastro Med Res. 4(2). GMR.000585. 2020.

DOI: $10.31031 /$ GMR.2020.04.000585

Copyright@ Tadao Tsuji, This article is distributed under the terms of the Creative Commons Attribution 4.0 International License, which permits unrestricted use and redistribution provided that the original author and source are credited.
Tadao Tsuji ${ }^{1 *}$, Sun $G^{1}$, Sugiyama $A^{1}$, Amano $Y^{1}$, Mano $S^{1}$, Shinobi $T^{1}$, Tanaka $H^{1}$, Kubochi $\mathbf{M}^{1}$, Ohishi $\mathrm{K}^{1}$, Moriya $\mathrm{Y}^{1}$, Ono $\mathbf{M}^{1}$, Masuda $\mathrm{T}^{1}$, Shinozaki $\mathrm{H}^{2}$, Kaneda $\mathbf{H}^{2}$, Katsura $\mathrm{H}^{2}$, Mizutani $\mathrm{T}^{2}$, Miura $\mathrm{K}^{2}, \mathbf{M ~ K a t o h}^{2}$, Yamafuji $\mathrm{K}^{3}$, Takeshima $\mathrm{K}^{3}$ and Okamoto $\mathrm{N}^{3}$

${ }^{1}$ Saitama Cooperative Hospital, Gastroenterology, Japan

${ }^{2}$ Saitama City Hospital, Gastroenterology, Japan

${ }^{3}$ Saitama City Hospital, Surgery, Japan

\section{Case Report}

We have experienced 27 cases of pancreatic incomplete divisum (PID), a type of malformation of the pancreatic duct, in the past 5 years. They consisted of 19 male and 8 female, aged 13-82 y/o. Symptomatic 21 cases were 19 male (calcified 18, non-calcified 1) and 2 female (non-calcified 1, IPMN 1). Asymptomatic cases were 6 (1 non-calcified male,5 female-all were non-users of alcohol. 3 cases were complicated with pseudocysts. Treatment procedures consisted of ESWL+endoscopy (via major papilla) 2, ESWL+endoscopy (via minor)13, endoscopy alone 4 (via minor). 1 case received pancreato- duodenectomy after medical treatment and 1 received pseudocyst resection in the tail without medical treatment. (Table 1) In the literature, reports about PID treatment are few, so we would like to show its treatment method in our hospital, especially 2 new procedures: Rendezvous pre-cut method and reverse balloon method-our new therapeutic procedures.

\section{Table 1:}

\begin{tabular}{|c|c|c|}
\hline \multicolumn{3}{|c|}{$<$ Treatment $>$} \\
\hline 1 & endo. alone & 3 (minor 3 ) \\
\hline 2 & ESWL+endo. & 16 (minor 14. major2) \\
\hline 3 & no therapy & 7 \\
\hline 4 & operation & 2 \\
\hline \multicolumn{3}{|c|}{ (1 post medical,1 primarily) } \\
\hline \multicolumn{3}{|c|}{$<$ prognoses $>$} \\
\hline \multicolumn{3}{|c|}{ Pain relapsing and /or stone recurrence 15/19=71\% } \\
\hline \multicolumn{3}{|c|}{ <Cancer occurence > } \\
\hline \multicolumn{3}{|c|}{ non } \\
\hline
\end{tabular}

\section{Rendezvous pre-cut method; 12 cases (Figure 1)}

Case 1 56-year old male: The guidewire, inserted through the major papilla, came out into the duodenum via the minor papilla. Along this guidewire, the minor papilla was cut by a needle type papillotome (KD-200Q-0721 Olympus) and the catheter was inserted into the minor papilla, then EPS was placed. This is our original procedure, a variant of the rendezvous method [1]. 


\section{Reverse balloon method; 3 cases (Figure 2,3)}

Case 2 13-year old female: She entered into our hospital complaining of reccurent epigastralgia. The guidewire, inserted into the major papilla, came out via Wirsung's duct, connecting branch, Santorini's duct and minor papilla into the duodenum. The minor papilla was cut by needle type papillotome (rendezvous pre-cut method), and a balloon catheter was inserted along the guidewire and the minor papilla was dilated from the reverses direction by a $4 \mathrm{~mm}$ dilation balloon, then EPS could be placed into the dorsal duct [1].

20 cases were diagnosed by ERP and 7 by MRCP. Symptomatic patients had a history of alchohol intake, while asymptomatic patients had no history. 17 calcified cases were all male, alcoholic and symptomatic. 2 symptomatic female cases consisted of 1 IPMN with the minor papilla located in the duodenal diverticulum, and 1 strange shaped IPD (Table 1). After therapy, 21 symptomatic cases became pain free, however calcified cases required treatments many times by pain relapsing. There were no cases of cancer occurrence or death after treatment (Table 2).

Radhika reported 1 case of IPD treated by reverse sphincterotomy of the minor papilla. They used sphincterome to cut the minor papilla [2].

In chronic pancreatitis of which the origin is unknown, many will be diagnosed as IPD by MRCP. Endoscopic treatment via the minor papilla is useful for their treatment. Alcohol intake is probably one reason for their symptom onset.

\section{Table 2:}

\begin{tabular}{|c|c|c|c|c|}
\hline \multicolumn{5}{|c|}{ Incomplete Pancreatic Divisum 2014. 4.1 -2020.2.5 } \\
\hline \multicolumn{5}{|c|}{$<$ Patient 27> } \\
\hline \multicolumn{5}{|c|}{ male 19 female 8 age $14-82$ y/o } \\
\hline \multicolumn{5}{|c|}{$<$ Diagnosis $>$} \\
\hline \multicolumn{5}{|c|}{ MRCP 7, ERP20 } \\
\hline \multicolumn{5}{|c|}{$<$ Primary complication $>$} \\
\hline \multicolumn{5}{|c|}{ pseudocyst 2 , pseudocyst+empyema 1} \\
\hline & & Symp. (+) & Symp. (-) & Alcoh (+) \\
\hline \multirow{2}{*}{ M stone } & $(+)$ & 17 & 0 & 17 \\
\hline & $(-)$ & 1 & 1 & 2 \\
\hline \multirow{2}{*}{ F stone } & $(+)$ & 0 & 0 & 0 \\
\hline & $(-)$ & 2 & 6 & 0 \\
\hline
\end{tabular}

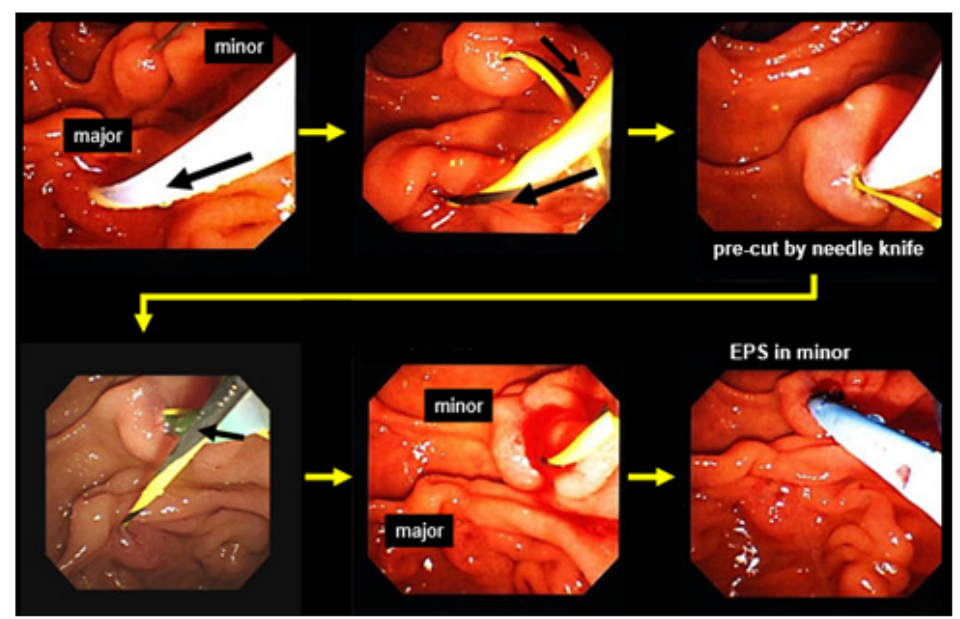

Figure 1: Rendezvous precut method: guidewire came back into the duodenum and pre-cutting of the minor was done then catheter was inserted into Santorini-duct. 


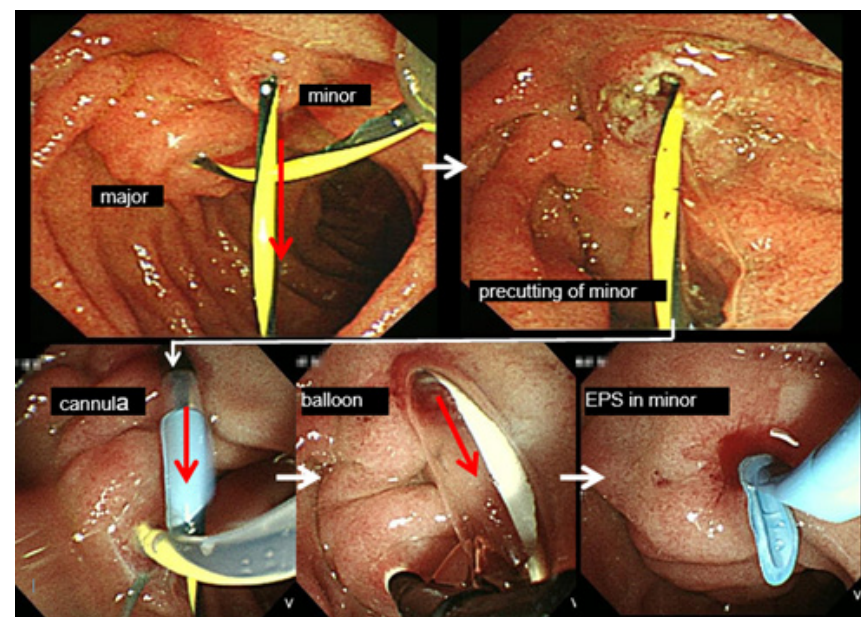

Figure 2: Rendezvous precut method + reverse balloon method.

After rendezvous precut method, balloon came out into duodenum, and minor was dilated, then EPS was placed via minor

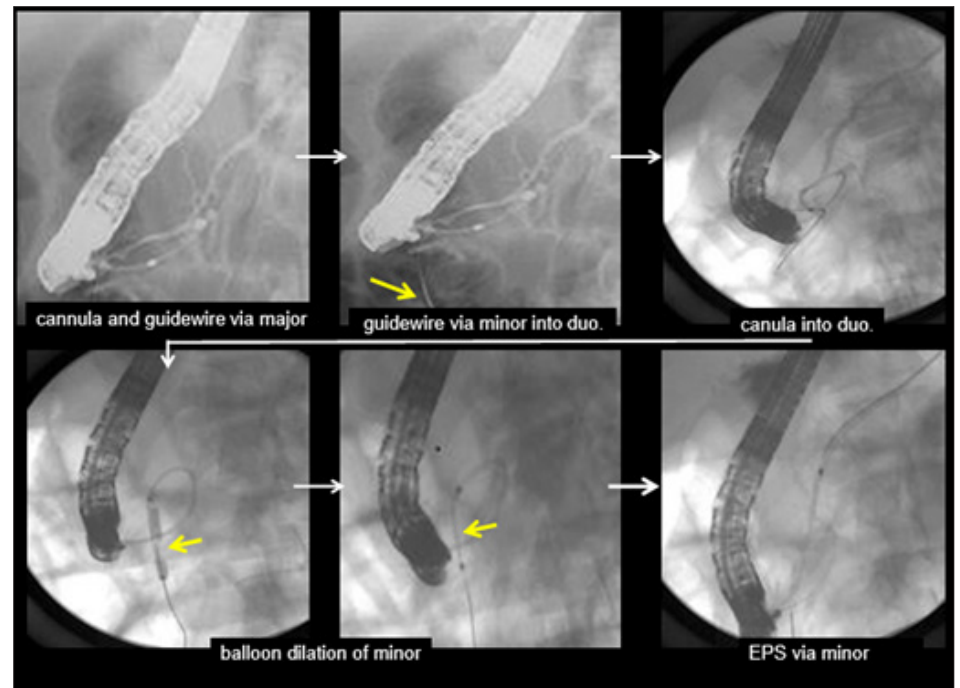

Figure 3: The same case as Fig 2.

\section{References}

1. Tsuji T, Sun G, Sugiyama A, et al. (2019) Endoscopic treatment of pancreatic diseases via duodenal minor papilla:135 cases treated by sphincterotomy, endoscopic pancreatic duct balloon dilation and pancreatic stenting. Ann of Clin Gastrointest and Hepato 3(1): 012-019.
2. Chavan R, Kalapala R, Nabi Z, et al. (2017) Reverse sphincterotomy of the minor papilla via the major papilla for chronic pancreatitis with incomplete pancreas divisum. Endoscopy 49(1): E119-E120.

For possible submissions Click below: 